\title{
Penerapan Sistem Kendali PID untuk KestabilanTwin- Tiltrotor dengan Metode DCM
}

\author{
Andi Dharmawan ${ }^{1}$, Sani Pramudita*2 \\ ${ }^{1}$ Jurusan Ilmu Komputer dan Elektronika, FMIPA UGM, Yogyakarta \\ ${ }^{2}$ Program Studi Elektronika dan Instrumentasi, FMIPA UGM, Yogyakarta \\ e-mail: 1harmawan@ugm.ac.id, ${ }^{* 2}$ sani.pramudita@mail.ugm.ac.id
}

\begin{abstract}
Abstrak
Twin-tiltrotor merupakan salah satu jenis dari multirotor yang memiliki dua buah baling-baling sebagai penggeraknya yang terletak di sisi kanan dan kiri dan dapat digerakkan secara longitudinal. Twin-tiltrotor memiliki sistem Vertical Take Off and Landing (VTOL), sehingga dapat melakukan hovering sewaktu-waktu dan dapat terbang menyerupai model fixed wing. Penelitian ini bertujuan untuk merancang sistem kestabilan pada saat tiltrotor melakuakn hovering menggunakan metode DCM dan kontrol PID.

DCM merupakan sebuah metode yang digunakan untuk mengubah data yang diperoleh dari sensor IMU (accelerometer, gyroscope, dan magnetometer) menjadi sudut yang digunakan sebagai acuan dari kestabilan terbang dari tiltrotor yang dikendalikan menggunakan algoritma PID. Hasil kendali PID akan mengendalikan tiltcopter dengan menggerakkan motor servo dan motor brushless.

Hasil pengujian menunjukkan bahwa, kestablian terbang pada tiltrotor dipengaruhi oleh peletakkan dari muatan serta letak dari titik center of gravity. Selain itu, dengan menggunakan metode DCM, hasil dari pengubahan nilai sensor menjadi sudut memiliki akurasi sebesar \pm 0.11 untuk sudut roll dan \pm 0.15 untuk sudut pitch. Untuk nilai PID pada sudut pitch adalah Kp 0.8, Ki 0.4, dan Kd 0.03, sedangkan untuk sudut roll adalah Kp 0.32, Ki 0.03, dan Kd 0.003.
\end{abstract}

Kata kunci-Tiltrotor, DCM, IMU.

\begin{abstract}
Twin-tiltrotor is a type of multirotor which has two propellers as propulsion located on the right and left of the body and can be moved longitudinally. Twin-tiltrotor has a Vertical Take Off and Landing system, so it can hover anytime and it can fly using fixed wing model. This study aims to design a system that can stabilize while hovering using DCM and PID control methods.

DCM is a method that transform data obtained from IMU sensor (accelerometer, gyroscope, and magnetometer) and used as a refrence angle of stability of a tiltrotor controlled by PID algorithm. The results of PID will control the servo and brushless motor.

The results of this study shows that the stability of the tiltrotor influenced by the position of the load and center of gravity. Beside that, by using the DCM, the result of conversion of sensor data into an angel, has an accuration \pm 0.11 for roll angle and \pm 0.15 for pitch angle. PID value

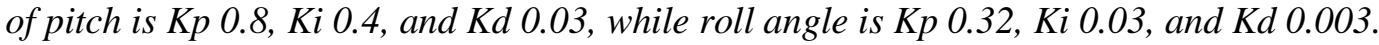

Keywords-Tiltrotor, DCM, IMU

Received June $23^{\text {th }}, 2014$; Revised June $14^{\text {th }}$, 2015; Accepted October $1^{\text {th }}, 2015$ 


\section{PENDAHULUAN}

$U$

nmanned Aerial Vehicle (UAV) atau pesawat tanpa awak, akhir-akhir ini menjadi sebuah tren baru pada bidang militer maupun non militer. UAV merupakan pesawat tanpa awak yang dapat dikendalikan dari jarak jauh sehingga tidak membutuhkan pilot untuk menerbangkannya. UAV memiliki berbagai jenis seperti dari fixed wing, multicopter, helicopter, dan lain-lain. Untuk multicopter contohnya, quadcopter yang memiliki 4 baling-baling, tricopter dengan 3 baling-baling, serta bicopter/twincopter yang memiliki 4 baling-baling.

UAV pada awalnya dikembangkan untuk keperluan militer seperti memata-matai daerah konflik, tapi kini penggunaan UAV sendiri sudah banyak dimanfaatkan untuk bidang selain militer seperti, pencarian dan penyelamatan korban bencana alam, mendeteksi aktivitas gunung berapi, dan masih banyak penggunaan UAV yang lainnya. Dengan bentuk fisik yang dapat dibuat kecil dan fleksibel, UAV dapat dimanfaatkan di daerah yang sulit dijangkau oleh manusia.

Tilt-twin copter merupakan salah satu jenis multicopter yang sedang dikembangkan akhir-akhir ini yang memiliki dua buah baling-baling sebagai penggeraknya. Baling-baling tersebut terletak disamping kanan dan kiri dari badan pesawat dan baling-baling ini dapat digerakkan secara longitudinal. Twincopter memiliki sistem Vertical Take Off and Landing (VTOL), sehingga tidak membutuhkan landasan pacu yang panjang untuk mengudara dan karena baling-baling dapat digerakkan secara longitudinal, maka twincopter dapat melakukan hovering sewaktu-waktu, selain itu juga twincopter memiliki jarak tempuh dan kecepatan yang dapat melebihi quadcopter karena baling-baling yang dapat diubah sehingga menyerupai model fixed wing [1].

Pada penelitian sebelumnya sistem kendali yang sudah digunakan adalah metode backstepping [2]. Selain itu juga sistem kendali penerbangan yang dapat digunakan pada tiltrotor salah satunya sistem kendali on/off. Pada penerapannya, sistem kendali on/off ini masih belum mampu menstabilkan tiltrotor dengan baik. Oleh karena itu, pada penelitian ini akan digunakan sistem kendali penerbangan menggunakan kendali PID agar lebih optimal.

\section{METODE PENELITIAN}

\subsection{Rancangan Sistem Secara Keseluruhan}

Sistem ini menggunakan sensor orientasi IMU untuk membaca sudut orientasi yang terbentuk antara sumbu bumi dengan sumbu pesawat, selanjutnya data dari sensor IMU masuk ke dalam arduino untuk diolah. Pada arduino, data-data yang didapatkan dari sensor akan diubah kedalam bentuk sudut roll dan pitch dengan menggunakan metode sensor fusion Direct Cosine Matrix (DCM). Hasil dari proses DCM menghasilkan sudut orientasi yaitu sudut roll dan sudut pitch. Sudut tersebut akan dibandingkan dengan nilai setpoint yang telah ditentukan. Dalam penelitian ini setpoint yang diberikan adalah sudut $0^{\circ}$ untuk masing-masing sudut yang akan menghasilkan nilai error. Nilai error tersebut akan diolah dengan metode PID dan hasil dari PID akan diubah menjadi PWM yang akan menggerakkan aktuator tiltrotor akan hovering menuju keadaan yang lebih seimbang. Hal tersebut dapat dilihat pada Gambar 1. 


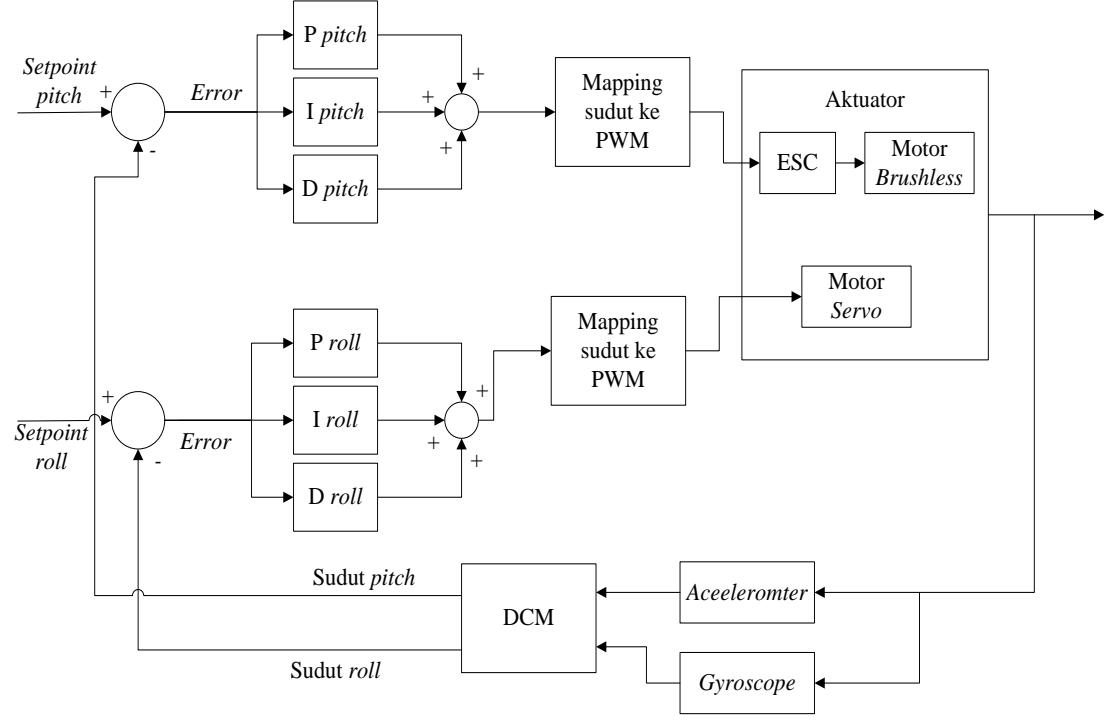

Gambar 1 Diagram blok rancangan sistem

\subsection{Rancangan Perangkat Keras pada Twin-Tiltcopter}

Badan utama tiltrotor memiliki dua tingkat dengan ketinggian. Tingkat bawah dari tiltrotor digunakan untuk meletakkan dua buah motor servo yang langsung terhubung dengan bagian sayap, sedangkan tingkat atas digunakan untuk meletakkan bagian elektronik, sensor, serta modul YS-1020.

Bagian sayap pesawat memiliki ukuran panjang $30 \mathrm{~cm}$ dan berdiameter $1 \mathrm{~cm}$. Bagian sayap ini langsung terhubung ke bagian badan utama dari tiltrotor. Pada bagian sayap terdapat tempat untuk meletakkan motor brushless dengan ukuran panjang dan lebar masing-masing 4 $\mathrm{cm}$. Gambar 2 dan Gambar 3 menggambarkan ukuran dari tiltrotor secara jelas.

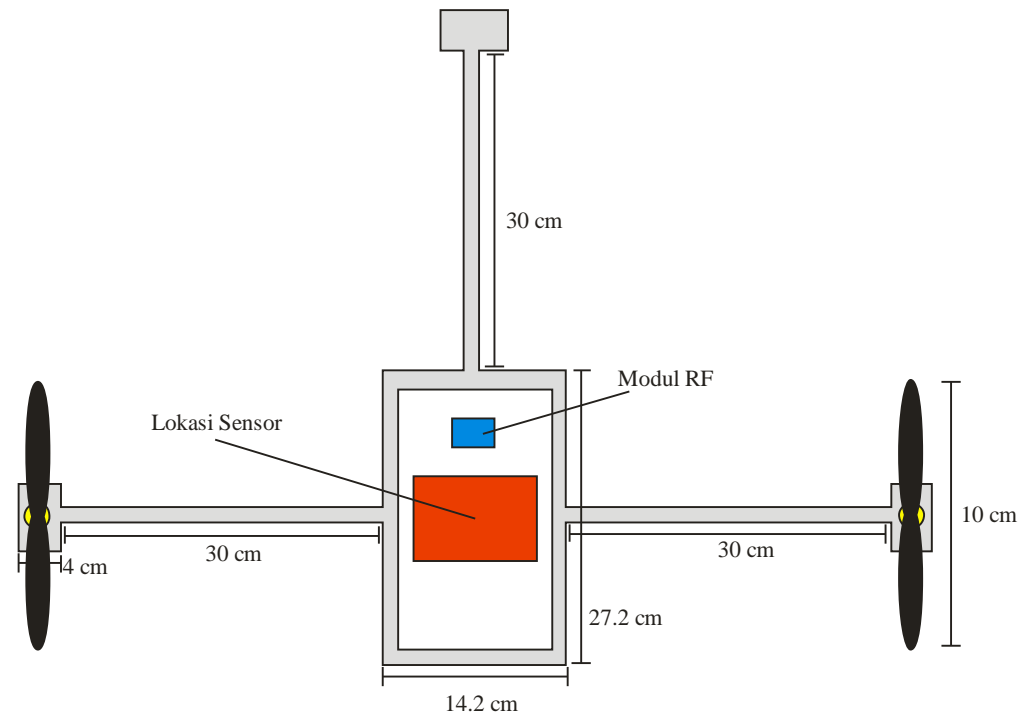

Gambar 2 Rancangan tiltrotor tampak atas 


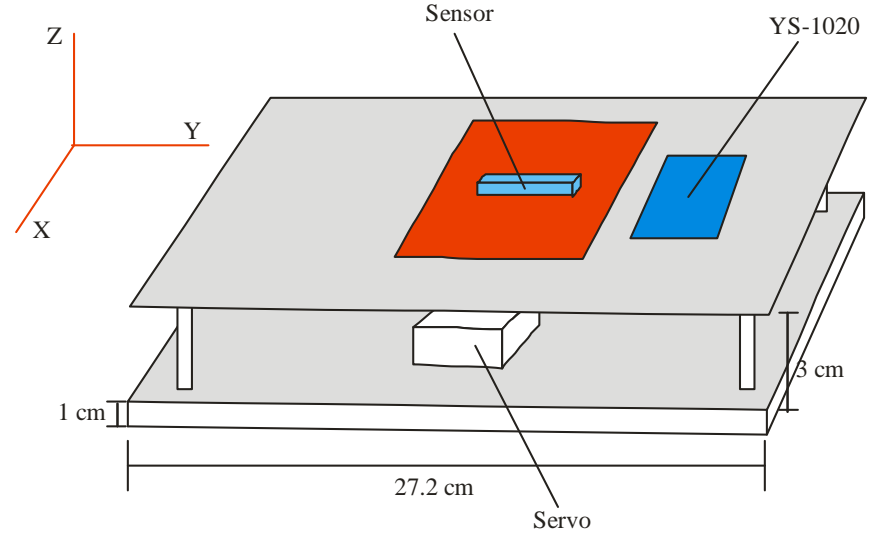

Gambar 3 Rancangan tiltrotor tampak samping

Peletakkan sensor IMU pada bagian atas disesuaikan dengan rancangan badan utama tiltrotor dengan sumbu y pada sensor menghadap ke arah bagian depan dari badan utama, sumbu x pada sensor menghadap ke arah bagian sayap tiltrotor, sedangkan sumbu z mengarah ke bagian bawah badan utama.

\subsection{Perancangan Perangkat Lunak}

Perangkat lunak yang ditanamkan pada arduino berfungsi untuk mengakses sensor serta memberikan algoritma untuk mengolah masukan tersebut sebagai keluaran dari sistem tiltrotor ini. Pemrograman dilakukan dengan bahasa pemrograman $\mathrm{C}++$. Pemrograman dilakukan menggunakan arduino IDE.

Fungsi utama dari arduino tersebut adalah mengolah data dari sensor dan menjaga agar tiltrotor dapat hovering dengan stabil. Gambar 4 merupakan diagram alir program pada tiltrotor.

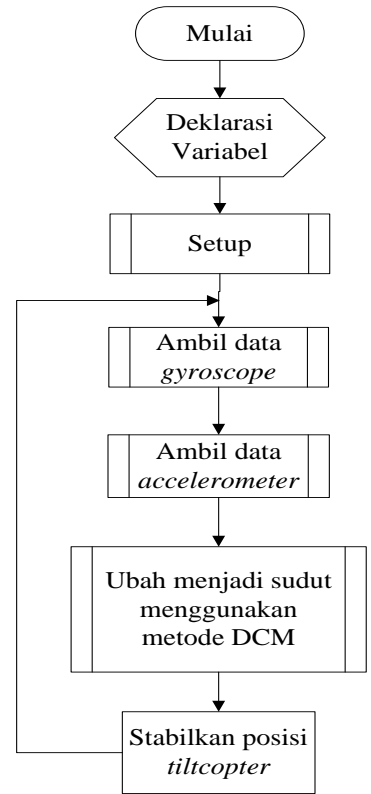

Gambar 4 Diagram alir program utama

Program dimulai dengan deklarasi variabel- variabel yang digunakan serta pengambilan library yang dibutuhkan. Setelah semuanya dideklarasikan, program akan berlanjut ke fungsi setup yang merupakan fungsi untuk melakukan penyettingan awal dari tiltcopter. 
Setelah fungsi setup dijalankan, program akan masuk ke dalam looping program dengan membaca data dari sensor accelerometer dan gyroscope. Data yang dihasilkan oleh sensorsensor tersebut akan diolah oleh arduino UNO untuk mengendalikan motor brushless dan motor servo pada tiltrotor agar dapat terbang dengan lebih seimbang.

\subsubsection{Pembacaan Sensor Orientasi}

Data dari masing-masing sensor diolah untuk mendapatkan sudut roll dan pitch.

Pengolahan data sensor tersebut menggunakan sensor IMU 10 DOF, tetapi pada pengaplikasiannya hanya digunakan accelerometer dan gyroscope. Setiap sensor memberikan 3 buah data yang merupakan sumbu dari sensor tersebut. Data dari masing-masing sensor diolah untuk mendapatkan sudut roll dan pitch [3] seperti pada Gambar 5(a) untuk sensor untuk sensor gyroscope dan Gambar 5(b) untuk sensor accelerometer. Pengolahan data sensor menjadi sudut roll dan pitch menggunakan metode Direct Cosine Matrix (DCM) [4].
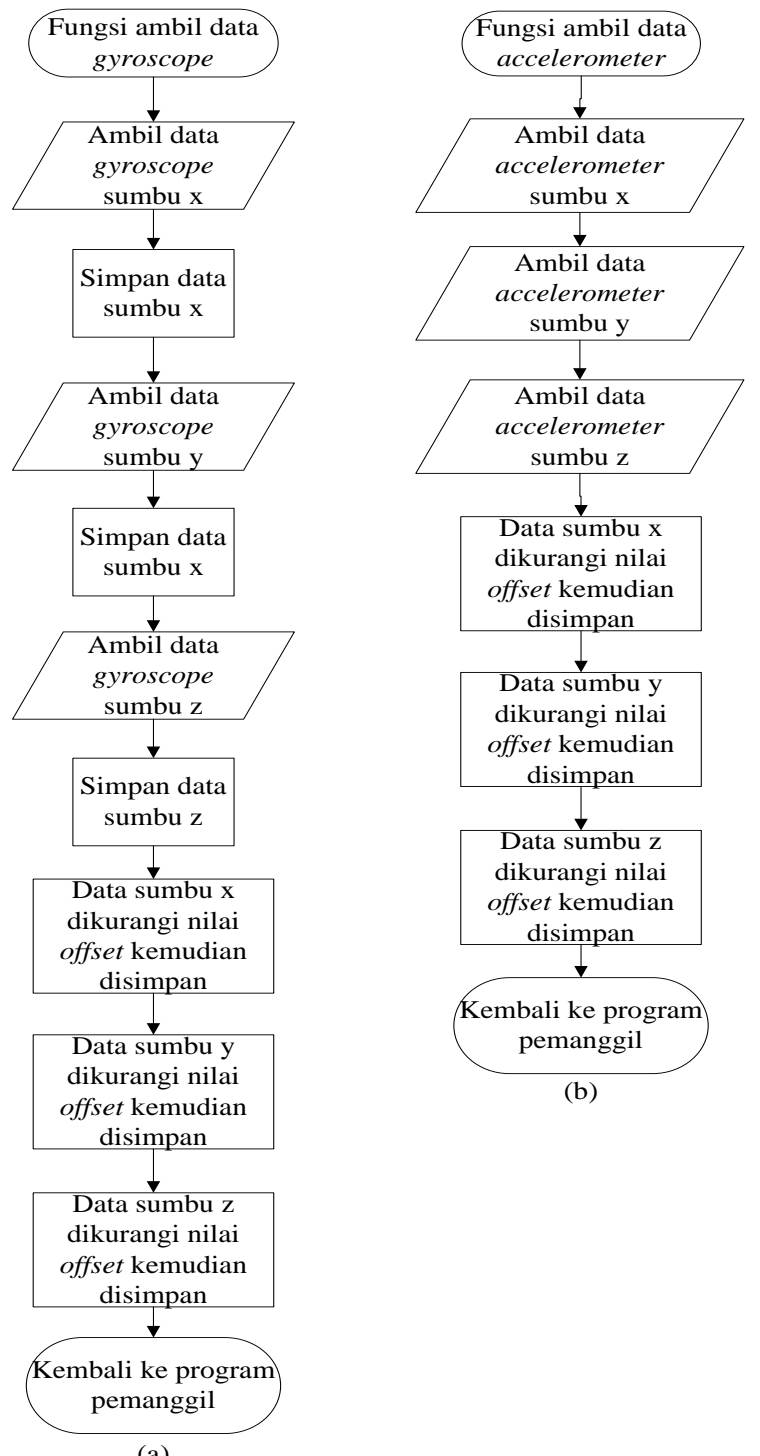

(b)

Gambar 5 Diagram alir pembacaan sensor (a)sensor gyroscope (b) sensor accelerometer 


\subsection{2. $\quad$ Direct Cosine Matrix (DCM)}

Untuk mendapatkan nilai sudut roll dan pitch, nilai-nilai dari sensor accelerometer dan gyroscope harus digabungkan menggunakan metode direct cosine matrix. Metode ini membaca nilai dari sensor gyroscope, kemudian nilai tersebut dirotasi sebanyak tiga kali sesuai dengan sumbu sensor seperti pada Gambar 6.

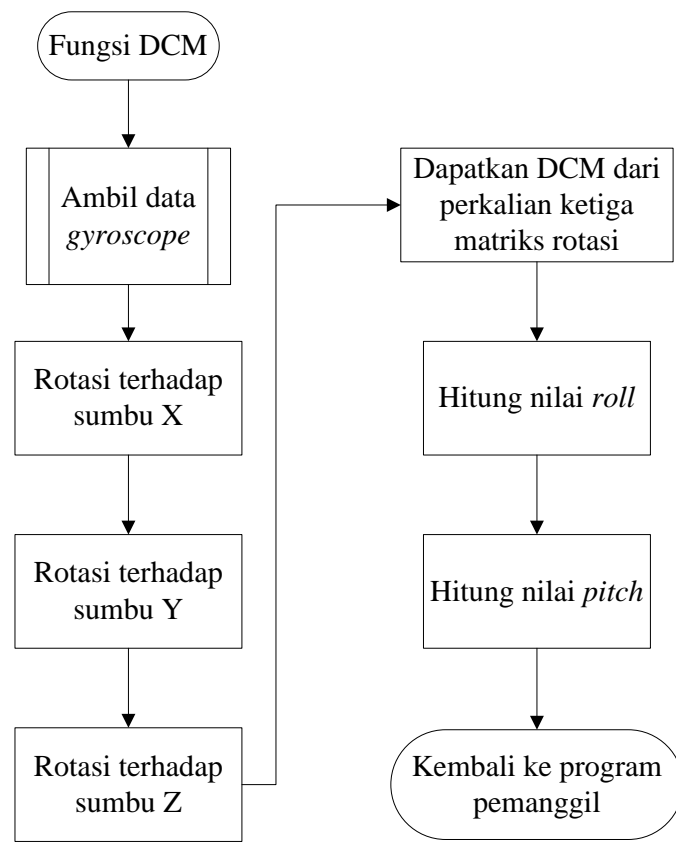

Gambar 6 Diagram alir DCM

Nilai-nilai tersebut akan diubah kedalam bentuk matrix sesuai dengan persamaan (1).

$R x=\left[\begin{array}{ccc}1 & 0 & 0 \\ 0 & \cos \phi & -\sin \phi \\ 0 & \sin \phi & \cos \phi\end{array}\right], R y=\left[\begin{array}{ccc}\cos \theta & 0 & \sin \theta \\ 0 & 1 & 0 \\ -\sin \theta & 0 & \cos \theta\end{array}\right], R z=\left[\begin{array}{ccc}\cos \Psi & -\sin \Psi & 0 \\ \sin \Psi & \cos \Psi & 0 \\ 0 & 0 & 1\end{array}\right]$

Dari persamaan (1) diatas, kemudian matriks-matriks tersebut dikalikan sehingga menghasilkan matriks DCM 3x3 seperti pada persamaan (2) berikut.

$\mathrm{R}=\left[\begin{array}{ccc}\cos \theta \cos \Psi & \sin \phi \sin \theta \cos \Psi-\cos \phi \sin \Psi & \cos \phi \sin \theta \cos \Psi+\sin \phi \sin \Psi \\ \cos \theta \sin \psi & \sin \phi \sin \theta \sin \Psi+\cos \phi \cos \Psi & \cos \phi \sin \theta \sin \Psi-\sin \phi \cos \Psi \\ -\sin \theta & \sin \phi \cos \theta & \cos \phi \cos \theta\end{array}\right]$

Bentuk umum dari matriks DCM adalah ditunjukkan pada persamaan (3) dan didapatkan nilai roll, pitch, dan yaw berdasarkan pada persamaan .

$$
R=\left[\begin{array}{lll}
R_{11} & R_{12} & R_{13} \\
R_{21} & R_{22} & R_{23} \\
R_{31} & R_{32} & R_{33}
\end{array}\right]
$$

Dari persamaan (3) diatas didapatkan nilai roll, pitch, dan yaw sebagai berikut, 
1.Nilai roll $(\phi)$ didapatkan dari persamaan (4)

$$
\begin{gathered}
\frac{\left(R_{32}\right)}{\left(R_{33}\right)}=\tan \phi \\
\phi=\arctan 2\left(\mathrm{R}_{32}, \mathrm{R}_{33}\right)
\end{gathered}
$$

2.Nilai pitch $(\theta)$ didapatkan dari persamaan (5)

$$
\begin{array}{r}
R_{31}=-\sin \theta \\
\theta=-\arcsin \left(R_{31}\right)
\end{array}
$$

\subsubsection{Kontrol PID}

Diagram alir pengontrol PID dijelaskan pada Gambar 7. Fungsi pengontrol PID dimulai dengan membaca sinyal dari remote control. Sinyal dari remote control yang masuk dalam PID berfungsi untuk mengatur setpoint dari masing-masig sudut roll dan pitch sehingga tiltcopter dapat digerakkan sesuai dengan keinginan pengguna.

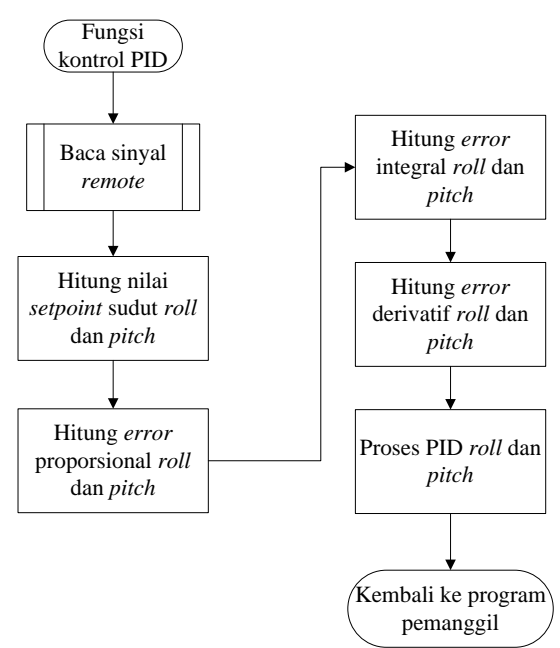

Gambar 7 Diagram alir kontrol PID

\subsection{Implementasi Perangkat Keras}

Rangka pesawat tiltrotor ini dibuat dengan menggunakan bahan alumunium.

Penggunaan alumunium dimaksudkan karena material tersebut kuat dan ringan. Ukuran badan pesawat memiliki panjang $27.2 \mathrm{~cm}$, lebar 14.2, serta tinggi $12 \mathrm{~cm}$. Sedangkan untuk panjang sayap pesawat masing-masing memiliki panjang $30 \mathrm{~cm}$ dan $4 \mathrm{~cm}$ untuk dudukan motor brushless, sehingga panjang keseluruhan sayap $34 \mathrm{~cm}$. Untuk sambungan sayap dengan motor servo digunakan plat berbentuk lingkaran dengan diameter $1.5 \mathrm{~cm}$. Mekanik dari tiltrotor dapat dilihat pada Gambar 8.

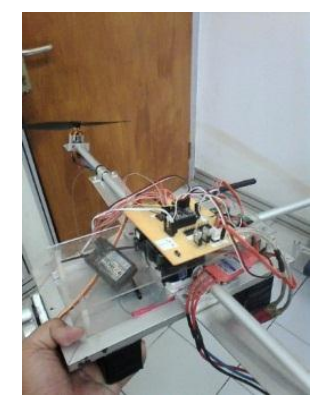

Gambar 8 Implementasi mekanik tiltrotor 


\section{HASIL DAN PEMBAHASAN}

\subsection{Pengujian Hasil DCM Sudut Pitch}

Pengujian dilakukan dengan cara menggantungkan tiltrotor dengan seutas tali dibagian lengan agar dapat berrotasi pada sumbu Y. Setiap pengukuran dicatat hasil pengukuran sudut yang didapat menggunakan busur derajat dan sudut yang dihasilkan dari hasil metode DCM. Pengukuran sudut dilakukan sebanyak 5 kali pada sumbu pitch, dengan variasi sudut $0^{\circ}, 30^{\circ}$, $45^{\circ}, 60^{\circ}$, dan $90^{\circ}$. Hasil pengujian dapat dilihat pada Tabel 1 .

Tabel 1 Hasil pengujian sudut pitch

\begin{tabular}{|c|c|c|c|c|c|c|c|}
\hline $\begin{array}{c}\text { Sudut } \\
\text { busur } \\
\left({ }^{\circ}\right)\end{array}$ & \multicolumn{5}{|c|}{ Sudut terukur pada sensor $\left({ }^{\circ}\right)$} & \multirow{2}{*}{$\begin{array}{c}\text { Rata- } \\
\text { rata }\end{array}$} & $\begin{array}{c}\text { Standar } \\
\text { Deviasi }\end{array}$ \\
\cline { 2 - 7 } & Data 1 & Data 2 & Data 3 & Data 4 & Data 5 & & \\
\hline $90^{\circ}$ & 85.20 & 85.20 & 84.90 & 85.00 & 84.80 & 85.02 & 0.19 \\
\hline $60^{\circ}$ & 59.40 & 59.90 & 60.00 & 59.50 & 59.90 & 59.74 & 0.27 \\
\hline $45^{\circ}$ & 45.40 & 45.40 & 45.30 & 45.20 & 44.80 & 45.22 & 0.25 \\
\hline $30^{\circ}$ & 29.90 & 29.80 & 29.80 & 29.70 & 29.90 & 29.82 & 0.08 \\
\hline $0^{\circ}$ & 0.10 & 0.20 & 0.10 & 0.30 & 0.10 & 0.16 & 0.09 \\
\hline$-30^{\circ}$ & -31.10 & -31.30 & -31.10 & -31.40 & -31.30 & -31.24 & 0.13 \\
\hline$-45^{\circ}$ & -44.50 & -44.50 & -44.30 & -44.20 & -44.20 & -44.34 & 0.15 \\
\hline$-60^{\circ}$ & -59.70 & -59.80 & -59.80 & -59.90 & -60.10 & -59.86 & 0.15 \\
\hline$-90^{\circ}$ & -83.50 & -83.50 & -83.50 & -83.50 & -83.60 & -83.52 & 0.04 \\
\hline \multicolumn{7}{|c|}{ Rata-rata } \\
\hline
\end{tabular}

Hasil yang diperoleh dari pengujian sudut pitch menunjukkan bahwa nilai dari standar deviasi bervariasi pada tiap-tiap sudut yang diuji. Dapat dilihat bahwa nilai standar deviasi benilai 0.04 hingga 0.27 . Berdasarkan data tersebut dapat dikatakan bahwa rata-rata standar deviasi dari sudut pitch sebesar 0.15 sehingga akurasi pembacaan sudut pitch sebesar \pm 0.15 .

\subsection{Pengujian Hasil DCM Sudut Roll}

Pengujian dilakukan dengan cara menggantungkan tiltrotor dengan seutas tali dibagian depan dan belakang agar dapat berotasi pada sumbu X. Setiap pengukuran dicatat hasil pengukuran sudut yang didapat menggunakan busur derajat dan sudut yang dihasilkan dari hasil metode DCM. Pengukuran sudut dilakukan sebanyak 5 kali pada sumbu roll, dengan variasi sudut $0^{\circ}, 30^{\circ}, 45^{\circ}, 60^{\circ}$, dan $90^{\circ}$. Hasil pengujian dapat dilihat pada Tabel 2.

Tabel 2 Hasil pengujian sudut roll

\begin{tabular}{|c|c|c|c|c|c|c|c|}
\hline \multirow{2}{*}{$\begin{array}{c}\text { Sudut } \\
\text { busur } \\
\left({ }^{\circ}\right)\end{array}$} & \multicolumn{5}{|c|}{ Sudut terukur pada sensor $\left(^{\circ}\right)$} & \multirow{2}{*}{ Rata-rata } & \multirow{2}{*}{$\begin{array}{c}\text { Standar } \\
\text { Deviasi }\end{array}$} \\
\cline { 2 - 6 } & Data 1 & Data 2 & Data 3 & Data 4 & Data 5 & & \\
\hline $90^{\circ}$ & 88.80 & 88.70 & 88.80 & 88.90 & 88.80 & 88.80 & 0.07 \\
\hline $60^{\circ}$ & 60.20 & 60.10 & 60.20 & 60.10 & 60.30 & 60.18 & 0.08 \\
\hline $45^{\circ}$ & 45.70 & 45.70 & 45.60 & 45.70 & 45.50 & 45.64 & 0.09 \\
\hline $30^{\circ}$ & 30.60 & 30.80 & 30.60 & 30.70 & 30.70 & 30.68 & 0.08 \\
\hline $0^{\circ}$ & 0.50 & 0.20 & 0.20 & 0.30 & 0.00 & 0.24 & 0.18 \\
\hline$-30^{\circ}$ & -30.80 & -30.90 & -30.70 & -30.70 & -30.70 & -30.76 & 0.09 \\
\hline$-45^{\circ}$ & -45.40 & -45.50 & -45.70 & -45.50 & -45.80 & -45.58 & 0.16 \\
\hline$-60^{\circ}$ & -59.90 & -59.80 & -59.90 & -59.70 & -59.80 & -59.82 & 0.08 \\
\hline$-90^{\circ}$ & -88.50 & -88.60 & -88.80 & -88.50 & -88.80 & -88.64 & 0.15 \\
\hline \multicolumn{7}{|c|}{ Rata-rata } \\
\hline
\end{tabular}


Hasil yang diperoleh dari pengujian sudut roll menunjukkan bahwa nilai dari standar deviasi bervariasi pada tiap-tiap sudut yang diuji. Dapat dilihat bahwa nilai standar deviasi benilai 0.07 hingga 0.18 . Berdasarkan data tersebut dapat dikatakan bahwa rata-rata standar deviasi dari sudut roll sebesar 0.11 sehingga akurasi pembacaan sudut roll sebesar \pm 0.11 .

\subsection{Pengujian Sistem Kestabilan Sudut Pitch}

Pada pengujian ini akan diberikan variasi nilai dari $\mathrm{Kp}, \mathrm{Ki}$, dan $\mathrm{Kd}$. Tahap pertama adalah memvariasikan nilai Kp hingga dapat membuat tiltrotor berosilasi tetapi dengan rentang nilai osilasi yang cukup kecil dan waktu tunak yang cepat [5]. Pada penelitian ini didapatkan nilai $\mathrm{Kp}$ sebesar 0.8 . setelah didapatkan nilai $\mathrm{Kp}$, kemudian nilai $\mathrm{Ki}$ divariasikan dengan memberikan simpangan sebesar $30^{\circ}$. Nilai $\mathrm{Ki}$ akan mempengaruhi steady-state error dari tiltrotor, sehingga ketika tiltirotor diberi simpangan maka akan langsung kembali ke nilai setpointnya [5]. Pada penelitian ini didapatkan nilai Ki yang terbaik sebesar 0.4. Kemudian nilai $\mathrm{Kd}$ divariasikan dengan memberikan simpangan sebesar $30^{\circ}$. Nilai Kd diharapkan mampu mengurangi osilasi yang terjadi pada tiltrotor. Nilai Kd yang terbaik pada penelitian ini bernilai 0.03 [5]. Dari ketiga nilai konstanta tersebut, tiltrotor sudah mampu menstabilkan sudut pitch, tetapi masih terjadi osilasi dengan rentang yang cukup kecil seperti pada Gambar 9 berikut.

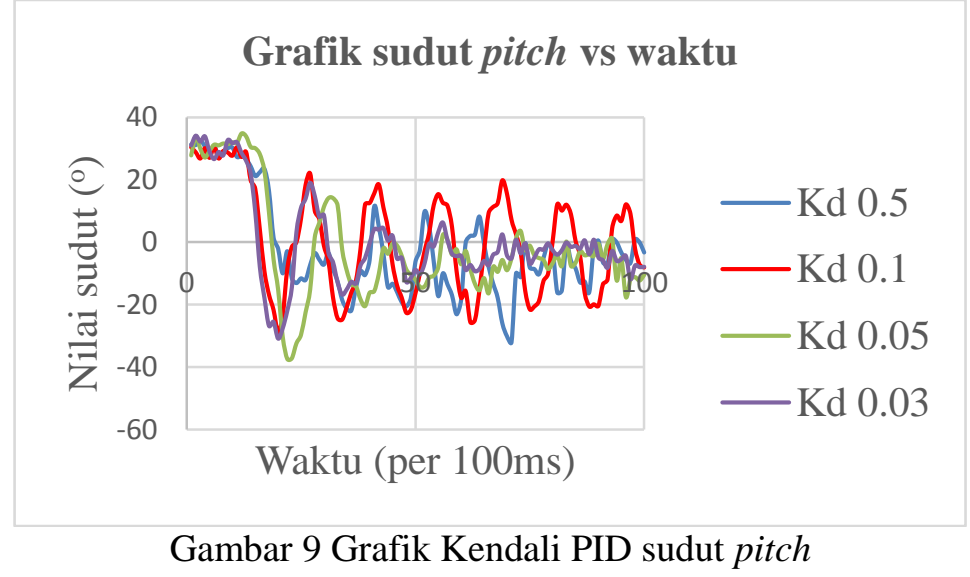

\subsection{Pengujian sistem kestabilan sudut roll}

Untuk pengujian sudut roll dilakukan perlakuan yang sama dengan pengujian pada sudut pitch yaitu dengan memberikan variasi nilai pada masing-masing konstanta $\mathrm{Kp}, \mathrm{Ki}$, dan $\mathrm{Kd}$, sehingga didapatkan nilai yang mampu membuat tiltrotor dapat melayang dengan stabil. Dari hasil penelitian yang dilakukan didapatkan nilai Kp sebesar 0.32, Ki sebesar 0.03, dan Kd sebesar 0.003 seperti yang ditunjukkan pada Gambar 10 .

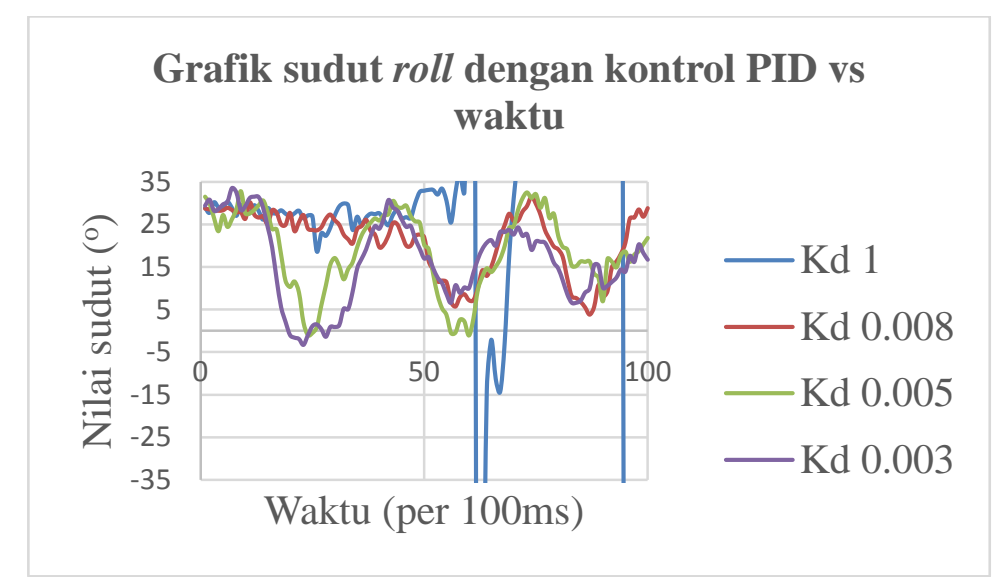

Gambar 10 Grafik kendali PID pada sudut roll 
Dari tersebut dapat dilihat bahwa terjadi pergeseran nilai setpoint sebesar $0^{\circ}$ menjadi sekitar $15^{\circ}$. Hal ini dikarenakan berat yang tidak seimbang pada kedua sisi tiltrotor.

\section{KESIMPULAN}

Dari hasil pengamatan, pengujian, dan analisis pada hasil yang diperoleh, kesimpulan yang dapat diambil adalah sebagai berikut.

1. Telah berhasil dibuat purwarupa penerapan sistem kendali PID untuk kestabilan twin-tiltrotor dengan metode DCM.

2. Pada tiltrotor ini, sudut yang dihasilkan dari penggabungan nilai dari dua buah sensor (accelerometer dan gyroscope) menggunakan metode DCM memiliki akurasi untuk sudut pitch adalah \pm 0.15 dan untuk sudut roll sebesar \pm 0.11 .

3. Konstanta proporsional, integral, dan derivatif yang digunakan pada:

- Pengontrol PID pitch : $\mathrm{Kp}=0.8, \mathrm{Ki}=0.4$, dan $\mathrm{Kd}=0.03$

- Pengontrol PID roll : $\mathrm{Kp}=0.32, \mathrm{Ki}=0.03$, dan $\mathrm{Kd}=0.003$

4. Letak dari titik center of gravity pada tiltrotor, mempengaruhi kestabilan terbang pada sudut roll.

5. Peletakkan muatan (kontroler dan sensor pendukung) pada tiltrotor mempengaruhi keseimbangan pada sudut pitch.

\section{SARAN}

Pada penelitian ini masih terdapat beberapa hal yang perlu disempurnakan. Berikut saran yang disampaikan untuk penelitian selanjutnya yang berhubungan.

1. Untuk meningkatkan stabilitas terbang pada tiltrotor perlu digunakan kendali PID dan sistem tuning yang lebih modern.

2. Perlu digunakan bahan dan desain yang lebih baik agar dapat meredam getaran yang terjadi akibat putaran dari baling-baling.

\section{DAFTAR PUSTAKA}

[1] Papachristos, C., Alexis, K., dan Tzes, A., 2011, Design and Experimental Attitude Control of an Unmanned Tilt-Rotor Aerial Vehicle, The $15^{\text {th }}$ International Conference on Advanced Robotics, Tallin, Estonia.

[2] Kendoul, F., Fatoni, I., dan Lozano, R., 2005, Modelling and Control of a Small Autonomous Aircraft Having Two Tilting Rotors, IEEE Transactions of Robotics, Austria.

[3] Patentstorm, 2007, Inertial Measurement Unit With Aiding From Roll Isolated Gyro, http://www.patentstorm.us/patents/506784.description.html, diakses tanggal 21 Maret 2013

[4] Premerlani, W. dan Bizard, P., 2009, Direction Cosine Matrix : Theory, http://gentlenav.googlecode.com/files/DCMDraft2.pdf, diakses tanggal 12 Desember 2013

[5] Ogata, K, 2002, Modern Control Engineering Fourth Edition, Prentice-Hall, USA. 